\title{
PENGARUH KADAR EKSTRAK BUMBU BRIYANI TERHADAP AKTIVITAS PENURUNAN KOLESTEROL SECARA INVITRO BESERTA KADAR FENOLIK DAN FLAVONOIDNYA
}

\author{
Achmad Wildan*, Erlita Verdia Mutiara, dan Dewi Ramonah \\ Sekolah Tinggi Ilmu Farmasi "Yayasan Pharmasi Semarang", Indonesia \\ "Email : achmadwildan58@gmail.com
}

\begin{abstract}
Abstrak
Hiperkolesterol atau kadar kolesterol yang tinggi dalam darah menjadi faktor risiko terjadinya penyakit kardiovaskuler dan stroke.. Penurunan kadar kolesterol dapat menggunakan obat sintetik atau menggunakan herbal yang dikonsumsi sehari hari sebagai pelengkap masakan. Bumbu biryani merupakan bumbu masakan dari Timur Tengah yang kaya akan kandungan rempah-rempah seperti kunyit, jinten, kapulaga, kayu manis, cengkeh dan sebagainya. Kandungan senyawa fenolik dan flavanoid yang tinggi di dalam bumbu biryani diduga memberikan kontribusi besar dalam penurunan kadar kolesterol. Tujuan penelitian ini adalah mengetahui pengaruhdari ekstrak bumbu biryani terhadap penurunan kadar kolesterol secara in vitro, dan mengetahui kandungan senyawa fenolik dan flavonoid bumbu biryani. Metode remaserasi menggunakan etanol 96\% untuk mengekstraksi bumbu biryani. Penetapan kadar fenolik total dilakukan menggunakan metode Folin-Ciocalteu, penetapan kadar flavonoid total menggunakan metode Alumunium Klorida, penetapan kadar kolesterol dilakukan menggunakan metode Liebermann Burcard kandungan fenolik total dalam ekstrak bumbu biryani sebesar 114,7663 mg GAE/g, kadar flavonoid total ekstrak bumbu biryani sebesar $81,4624 \pm 5,8558 \mathrm{mg} Q \mathrm{QE} / \mathrm{g}$, dan ekstrak bumbu biryani dengan konsentrasi 700 bpj dapat menurunkan kolesterol sebesar 45,73\%. Ekstrak bumbu biryani mengandung senyawa senyawa antioksidan seperti fenolik dan flavonoid yang berperan dalam penurunan kadar kolesterol.
\end{abstract}

Kata kunci: biryani, fenolik total,flavonoid total, kolesterol

\section{PENDAHULUAN}

Hiperkolesterol atau kadar kolesterol yang tinggi dalam darah menyebabkan penyakit gangguan metabolisme kolesterol atau hiperlipidemia (Siregar, 2015). Tingginya kadar kolesterol darah menjadi faktor risiko terjadinya penyakit kardiovaskuler dan stroke disamping hipertensi, gula darah, dan kurangnya aktifitas fisik (Perkeni, 2015). Berdasarkan NCD Country Profiles (2011), sekitar 30\% kematian di Indonesia disebabkan penyakit kardiovaskuler.

Kadar kolesterol total dalam darah dapat diturunkan melalui berbagai cara, salah satu penggunaan obat jenis simvastatin, sistem kerjanya adalah menghambat aktivitas enzim 3hidroksi-3-metil-glutaril- koenzim A (HMG-CoA) reduktase yang berfungsi sebagai katalis pembentukan kolesterol ( Drazen, dkk. 2008). Golongan statin ini memiliki kelemahan jika digunakan dalam jangka waktu lama. Salah satu menyebabkan efek samping miopati dan rhabdomiolisis sehingga dapat mengakibatkan terbatasnya mobilitas, dan toksisitas hepar (Rumanti dan Rizna, 2011). Untuk mengatasi masalah tersebut, salah satunya dilakukan penelitian menggunakan tanaman herbal yang dikembangkan fungsinya sebagai antihiperlipidemia.

Bumbu biryani berisi campuran rempah - rempah yang mengandung senyawa - senyawa antioksidan yang dapat menurunkan kolesterol melalui mekanisme pengikatan kolesterol oleh senyawa-senyawa tersebut seperti salah satunya oleh senyawa flavonoid sehingga kadarnya dalam darah akan turun (Sargowo, 2005). Campuran rempah - rempah ini berasal dari tanaman herbal antara lain kunyit, jinten, kapulaga, kayu manis, daun salam, ketumbar, jahe, bawang bombay dan bawang putih. Salah satu senyawa antioksidan pada bumbu biryani adalah kurkumin yang merupakan golongan senyawa fenolik yang banyak terdapat pada tanaman herbal (Yurttas, dkk., 2002). Hal ini mendorong dilakukannya penelitian pengaruh pemberian ekstrak bumbu biryani terhadap kadar kolesterol secara in vitro. 


\section{METODE PENELITIAN \\ Alat dan Bahan}

Penelitian ini dilakukan di Laboratorium Farmasi, Sekolah Tinggi Ilmu Farmasi Yayasan Pharmasi Semarang. Bahan yang digunakan dalam penelitian ini adalah bumbu biryani yang diperoleh dari pasar tradisional Mekkah Saudi Arabia.Bahan kimia yang digunakan adalah kurkumin, etanol $96 \%$, etanol $70 \%$, resorsinol, reagen Folin-ciocalteu, $\mathrm{Na}_{2} \mathrm{CO}_{3} 7 \%$, rutin, $\mathrm{NaNO}_{2}$ $10 \%, \mathrm{AlCl}_{3} 10 \%, \mathrm{NaOH} 10 \%$, asam askorbat, asam oksalat $1 \%$, aquabidest, dapar fosfat $0,2 \mathrm{M}(\mathrm{pH}$ 6,6), $1 \mathrm{ml} \mathrm{K} 3 \mathrm{Fe}(\mathrm{CN})_{6} 1 \%, \mathrm{FeCl}_{3} 0,1 \%$, baku kolesterol, asam asetat anhidrat, kloroform, asam sulfat pekat, aquadest.

Alat yang digunakan dalam penelitian ini adalah Spektrofotometer UV-Vis double beam (Shimadzu UV-Vis 1700 series), neraca analitik (Santorius 2402), rotary vacum evaporator, alatalat gelas (iwaki pirex), waterbath, ayakan 30/40, tabung reaksi, pipa kapiler, plat tetes, chamber, lempeng Silika Gel GF 254, lampu UV 254 nm, kuvet, filler, vortex, stopwatch.

\section{Prosedur Percobaan}

Serbuk bumbu biryani sebanyak 200 gram diremaserasi selama 3 hari dengan cara hari pertama direndam dengan pelarut etanol konsentrasi 96\% sebanyak $1000 \mathrm{~mL}$, hari kedua ekstrak disaring menggunakan kain flannel kemudian ampas direndam menggunakan pelarut etanol 96\% sebanyak $500 \mathrm{~mL}$, hari ketiga ekstrak disaring lagi kemudian ampas direndam lagi menggunakan pelarut etanol $70 \%$ sebanyak $500 \mathrm{~mL}$. Ektrak digabung kemudian dimasukkan ke dalam cawan porselen dan diuapkan menggunakan rotary vacum evaporator dan waterbath hingga diperoleh ekstrak kental

Kandungan fenolik total pada ekstrak serbuk bumbu biryani ditentukan dengan menggunakan metode spektrofotometri.. Pertama-tama dibuat baku resorsinol dengan seri konsentrasi 1,5 $\mu \mathrm{g} / \mathrm{ml}, 2 \mu \mathrm{g} / \mathrm{ml}, 2,5 \mu \mathrm{g} / \mathrm{ml}, 3 \mu \mathrm{g} / \mathrm{ml}, 3,5 \mu \mathrm{g} / \mathrm{ml}$, dan $4 \mu \mathrm{g} / \mathrm{ml}$. Deret seri diukur absorbansinya dengan Spektrofotometri dengan panjang gelombang $740 \mathrm{~nm}$. Selanjutnya dihitung regresi linearnya sebagai kurva baku. Selanjutnya sebanyak $150 \mu \mathrm{L}$ ekstrak sampel $1 \%$ ditambah 0,4 mL pereaksi Folin-Ciocalteu dan dibiarkan 8 menit, selanjutnya ditambah $4,0 \mathrm{ml} \mathrm{Na} \mathrm{CO}_{3} 7 \%$ dan ditambah aquabidest sampai $10 \mathrm{ml}$. Kemudian diukur absorbansinya. Pengukuran dilakukan sebanyak 3 replikasi. Kandungan fenolik total dinyatakan dalam mg ekivalen asam galat setiap 1 gram ekstrak.

Kandungan flavonoid total pada ekstrak bumbu biryani ditentukan dengan metode Alumunium Klorida dan dianalisis menggunakan spektrofotometer. Pertama-tama dibuat baku rutin dengan seri konsentrasi $30 \mu \mathrm{g} / \mathrm{ml}, 35 \mu \mathrm{g} / \mathrm{ml}, 40 \mu \mathrm{g} / \mathrm{ml}, 45 \mu \mathrm{g} / \mathrm{ml}, 50 \mu \mathrm{g} / \mathrm{ml}$, dan $55 \mu \mathrm{g} / \mathrm{ml}$. Deret seri diukur absorbansinya dengan Spektrofotometri dengan panjang gelombang $509 \mathrm{~nm}$. Selanjutnya dihitung regresi linearnya sebagai kurva baku. Selanjutnya ekstrak sebanyak $1,0 \mathrm{ml}$ ditambah $4 \mathrm{ml}$ aquades dan $0,3 \mathrm{ml}$ larutan $\mathrm{NaNO}_{2} 10 \%$ dalam labu takar $10 \mathrm{ml}$, didiamkan 6 menit. Setelah itu larutan ditambah dengan $0,3 \mathrm{ml} \mathrm{AlCl}{ }_{3} 10 \%$ dan didiamkan 5 menit, ditambah 4 $\mathrm{ml} \mathrm{NaOH} 10 \%$ dan aquabidest sampai tanda batas. blanko berisi semua pereaksi yang digunakan tanpa rutin atau sampel ekstrak. Pengukuran dilakukan sebanyak 3 replikasi. Kandungan flavonoid total dinyatakan sebagai mg ekivalen kuersetin tiap 1 gr ekstrak..

Uji Aktivitas antikolesterol secara in vitro menggunakan metode Lieberman-Burchard. Sampel ekstrak dibuat dengan konsentrasi 300, 400, 500, 600 dan 700 bpj. Masing-masing konsentrasi ekstrak dipipet 5,0 mL dan ditambahkan larutan kolesterol 320 bpj dalam kloroform sebanyak 5,0 $\mathrm{mL}$. Setelah itu diaduk dengan vortex hingga diperoleh supernatan. Sebanyak 5,0 mL supernatan tersebut ditambah $2,0 \mathrm{~mL}$ asam asetat anhidrat dan $0,1 \mathrm{~mL}$ asam sulfat pekat, dibiarkan selama 18 menit di dalam tempat gelap hingga larutan berwarna hijau. Pengukuran absorbansi sampel dilakukan dengan spektrofotometer dengan panjang gelombang 673,6 $\mathrm{nm}$.

\section{HASIL DAN PEMBAHASAN}

Metode yang digunakan untuk pengukuran kadar fenolik total ekstrak bumbu biryani adalah metode Folin-Ciocalteu. Hasil pengukuran larutan baku seri resorsinol diperoleh kurva baku dengan persamaan regresi $y=0,0058 x-0,019$ dengan nilai $R$ sebesar 0,9997 (Gambar 1). 


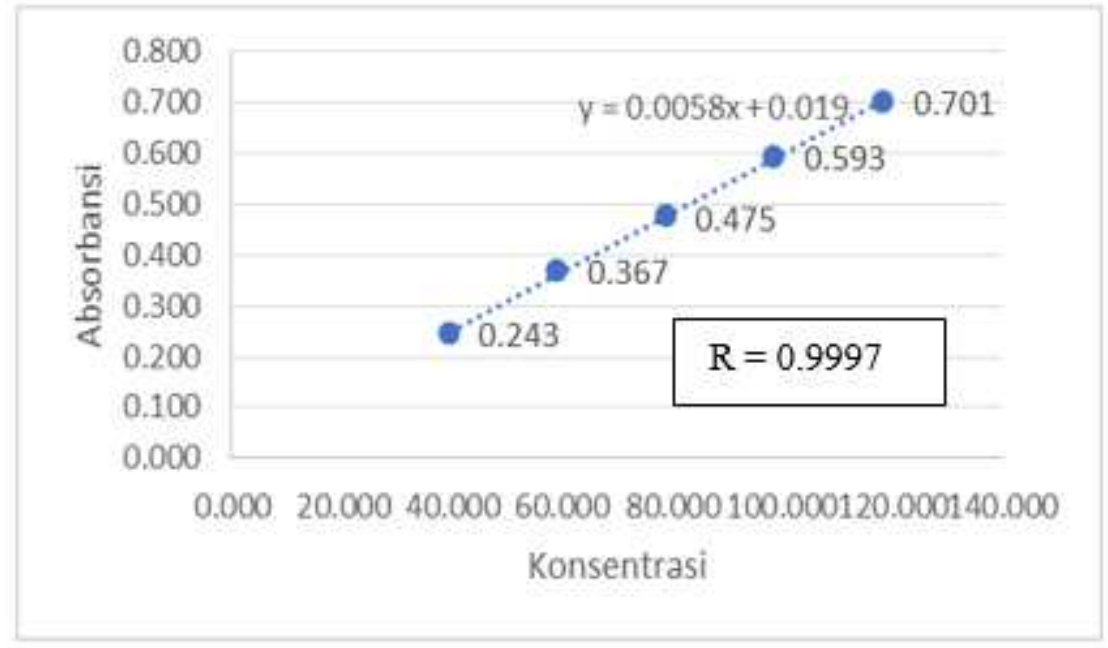

Gambar 1. Kurva kalibrasi resorsinol pada panjang gelombang $740 \mathrm{~nm}$

Pengukuran kadar fenolik total ekstrak bumbu biryani sebanyak 3 kali replikasi dengan pereaksi Folin-Ciocalteu menggunakan metode spektrofotometer (Tabel. 1).

Tabel 1. Hasil Pengukuran Kadar Fenolik Total Ekstrak Bumbu Biryani

Replikasi

Kandungan Fenolik Total

(mg GAE/g ekstrak)

\begin{tabular}{ll}
\hline 1 & 116.5998 \\
2 & 117.9692 \\
3 & 109.7300 \\
$\mathrm{X} \pm \mathrm{SD}$ & $114.7663 \pm 4.4150$ \\
\hline
\end{tabular}

Pengukuran kadar flavonoid total ekstrak bumbu biryani menggunakan metode kolorimetri menggunakan pereaksi alumunium klorida dengan baku rutin. Hasil pengukuran absorbansi pada beberapa konsentrasi yaitu $30 \mu \mathrm{g} / \mathrm{ml}, 35 \mu \mathrm{g} / \mathrm{ml}, 40 \mu \mathrm{g} / \mathrm{ml}, 45 \mu \mathrm{g} / \mathrm{ml}, 50 \mu \mathrm{g} / \mathrm{ml}$, dan $55 \mu \mathrm{g} / \mathrm{ml}$ menghasilkan kurva baku dengan bentuk persamaan regresi linier antara absorbansi dengan konsentrasi sebesar $y=0,0058 x+0,019$ dengan nilai R sebesar 0,9997 (Gambar 2).

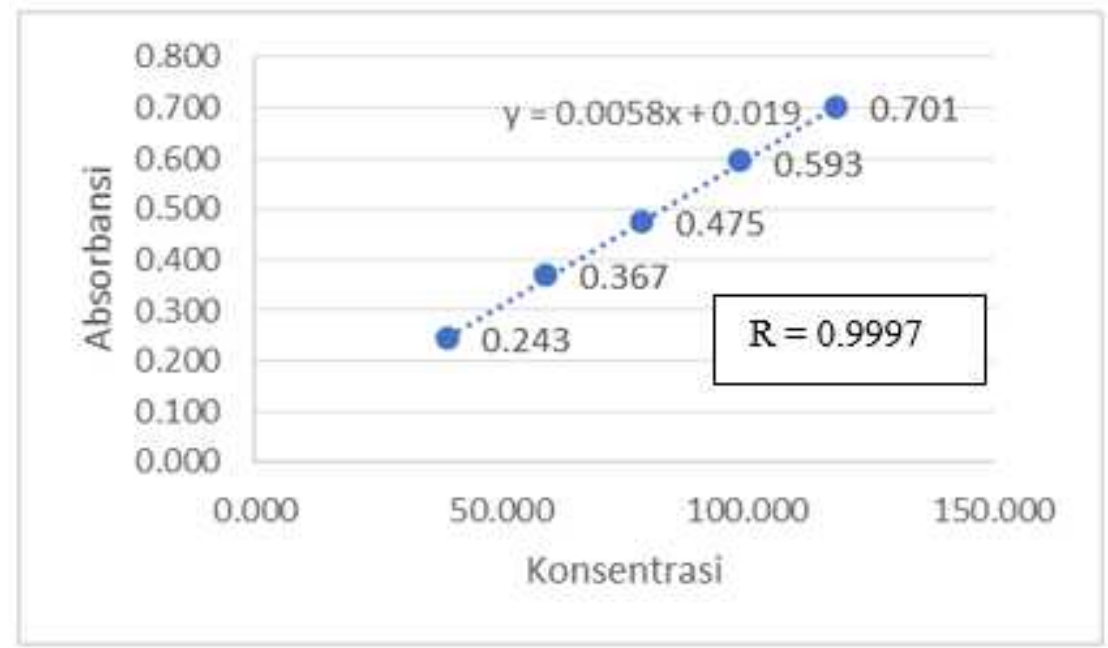

Gambar 2. Kurva kalibrasi Rutin pada panjang gelombang 509 nm

Pengukuran kadar flavonoid total ekstrak bumbu biryani sebanyak 3 kali replikasi dengan pereaksi alumunium klorida menggunakan metode spektrofotometri (Tabel. 2). 
Tabel 2. Hasil Pengukuran Kadar Flavonoid Total Ekstrak Bumbu Biryani

\begin{tabular}{rc}
\hline Replikasi & $\begin{array}{c}\text { Kandungan Flavonoid Total } \\
\text { (mg QE/g ekstrak) }\end{array}$ \\
\hline 1 & 85.5767 \\
2 & 84.0523 \\
3 & 74.7583 \\
$\mathrm{X} \pm \mathrm{SD}$ & $81.4624 \pm 5.8558$ \\
\hline
\end{tabular}

Pengukuran penurunan kadar kolesterol ekstrak bumbu biryani menggunakan metode Lieberman-Burchard dengan alat spektrofotometer pada panjang gelombang 673,6 nm (Tabel 3).

Tabel 3. Data Penurunan Kadar Kolesterol Ekstrak Bumbu Biryani

\begin{tabular}{cc}
\hline Konsentrasi Ekstrak (bpj) & Penurunan Kadar (\%) \\
\hline 300 & 22,9641 \\
400 & 38.9220 \\
500 & 40.2598 \\
600 & 43,052 \\
700 & 45,7275 \\
\hline
\end{tabular}

Kandungan fenolik total ekstrak bumbu biryani diukur dengan reagen Folin-Ciocalteu menggunakan alat spektrofotometer UV-Vis. Kandungan senyawa fenolat (garam alkali) atau gugus fenolik-hidroksi yang terdapat didalam ekstrak akan membentuk kompleks molibdenumtungsten yang berwarna biru setelah bereaksi dengan asam heteropoli yang ada di dalam reagen Folin-Ciocalteau. $\mathrm{Na}_{2} \mathrm{CO}_{3}$ ditambahkan untuk memberikan kondisi basa agar disosiasi proton pada senyawa fenolik menjadi ion fenolat dapat terjadi, sehingga reaksi dengan reagen Folin-Ciocalteau dapat terjadi (Wachidah, 2013). Larutan standar yang digunakan adalah resorsinol. Senyawa ini merupakan golongan fenolik yang mempunyai gugus $\mathrm{OH}$ posisi meta dan tersedia dalam bentuk murni. Berdasarkan hasil pengukuran, kandungan fenolik total dalam ekstrak bumbu biryani sebesar 114,7663 mg GAE/g, artinya dalam setiap gram ekstrak setara dengan 114,7663 mg resorsinol. Menurut Mongkolsilp, dkk (2004), penelitian pada lima tanaman obat yang terdapat di Thailand memberikan hasil semakin tinggi kandungan fenolik total maka aktivitas peredaman radikal bebas DPPH akan semakin tinggi. Hal ini disebabkan karena adanya Cincin aromatik yang mengikat beberapa gugus hidroksi yang berperan sebagai donor hidrogen sehingga mempunyai kemampuan meredam oksigen reaktif (Candra, 2014).

Metode yang dipakai dalam pengukuran kadar flavonoid total adalah spektrofotometri dengan pereaksi $\mathrm{AlCl}_{3}$ dan mengunakan baku rutin. $\mathrm{AlCl}_{3}$ bereaksi dengan gugus hidoksil dari struktur flavonoid membentuk ikatan komplek dan pengukuran absorbansi menggunakan spektrofotometer UV-vis.

Kadar falavonoid total pada ekstrak bumbu biryani diperoleh dari perhitungan melalui cara memasukkan nilai absorbansi pada kurva standar rutin sehingga diperoleh kadar flavonoid total rata-rata ekstrak bumbu biryani sebesar 81,4624 $\pm 5,8558 \mathrm{mg}$ QE/g, yang berarti dalam setiap gram ekstrak setara dengan 81,4624 mg rutin. Menurut Casachi dan Ogawa cit Rianti, dkk. (2013), sistem kerja flavonoid dalam menurunkan kadar kolesterol dalam darah melalui penghambatan kerja enzim HMG Co-A reduktase. Fungsi kerja enzim tersebut adalah merubah HMG Co-A menjadi mevalonat. Sehingga jika sistem kerja HMG Co-A reduktase dihambat maka proses pembentukan mevalonat juga ikut terhambat. Mekanisme kerja flavonoid tersebut hampir sama dengan mekanisme obat antihiperlipidemia golongan statin atau golongan inhibitor HMG Co-A reduktase (Sukandar, 2008).

Analisis penurunan kadar kolesterol ekstrak bumbu biryani menggunakan metode Lieberman-Burchard. Metode ini menggunakan pereaksi asam asetat anhidrat dan asam sulfat pekat. Asam asetat anhidrat berfungsi untuk mengekstraksi kolesterol, memastikan media bebas air serta membentuk turunan asetil sehingga direaksikan dengan asam sulfat pekat akan menghasilkan kompleks berwarna hijau kebiruan (Anggraini, 2017) 
Berdasarkan persen penurunan kadar kolesterol yang diperoleh, ekstrak bumbu biryani dengan konsentrasi 700 bpj dapat menurunkan kolesterol sebesar 45,73\%, sedangkan dengan konsentrasi 300 - 600 bpj penurunan kolesterol tidak stabil. Hal ini berkaitan saat melakukan preparasi adanya kesalahan dalam pemipetan sampel atau kurangnya homogenitas sampel dengan reagen lainnya.

\section{KESIMPULAN}

Ekstrak bumbu biryani mengandung senyawa - senyawa fenolik dan flavonoid yang berperan dalam penurunan kadar kolesterol secara in vitro.

\section{DAFTAR PUSTAKA}

Anggraini, D.I dan Ali, M.M. (2017), Uji Aktivitas Antikolesterol Ekstrak Etanol Daun Binahong (Anredera cordifolia (Ten) Steenis) Secara In Vitro. Jurnal Ilmiah Kesehatan, 9(1) pp. 1 - 6.

Casaschi et al.( 2004 ) dan ogawa et al (2005), dalam Ranti, G.C., Fatimawali, Wehantouw, F. (2013), Uji Efektivitas Ekstrak Flavonoid dan Steroid dari Gedi (Abelmoschus manihot) Sebagai Anti Obesitan dan Hipolipidemik Pada Tikus Putih Jantan Galur Wistar. Jurnal Ilmiah Farmasi UN.

Chandra S, Khan S, Avula B, Lata H, Yang M.H., ElSohly M.A., (2014), Assessment of Total Phenolic and Flavonoid Content, Antioxidant Properties, and Yield of Aeroponically and Conventionally Grown Leafy Vegetables and Fruit Crops: A Comparative Study. Evid Based Complement Alternat Med.pp. 1-9.

Drazen, J.M., Jarcho, J.A., Morrissey, S., and Curfman G.D., (2008), Cholesterol lowering and ezetimibe. $N$ Engl J Med ; 358(14):1507-8SRAT, 2 (2).

Mongkolsilp S, Pongbupaki I, and Sae-Lee N. (2004), Radical Scavenging Activity and Total Phenolic Content of Medicinal Plants Used in Primary Health Care. SWU J Pharm Sci.;9(1):32-5.

NCD Country Profiles., (2011), Indonesia. Available from: http://www.who.int/ nmh/ countries/idn_en.pdf. Diakses : 28 Oktober 2015.

Perkeni, (2015), Panduan Pengelolaan Dyslipidemia di Indonesia. Jakarta.

Rumanti dan Rizna T., (2011), Efek Propolis terhadap Kadar Kolesterol Total pada Tikus Model Tinggi Lemak. Universitas Kristen Maranatha. Bandung

Sargowo, D., (2005), Peran Lipid dan Oksidasi Lipoprotein pada Patogenesa Aterosklerosis. Siregar, R., (2015), The Effect Of Eugenia polyantha Extract On LDL Cholesterol. Artikel review: J MAJORITY, 4, pp. $85-92$

Universitas Brawijaya. Malang

Sukandar,E.Y., Andrajati, R., Sigit, J.I dan kusnandar. (2008), ISO Farmakoterapi. Jakarta: ISFI (Ikatan Sarjana Farmasi Indonesia).Hal 111-117.

Wachidah, L. N. (2013), Uji Aktivitas Antioksidan serta Penentuan Kandungan Fenolat dan Flavonid Total dari Buah Parijto. Skripsi. Fakultas Kedokteran dan Ilmu Kesehatan Universitas Islam Negeri Syarif Hidayatullah, Jakarta

Yurttas, H.C., Schafer, H.W. and Warthesen, J.J. (2000). Antioxidant activity of nontocopherol hazelnut (Corylus spp.) phenolics. Journal of Food Science 65: 276280. 